\title{
Can high-flow nasal cannula reduce the rate of reintubation in adult patients after extubation? A meta-analysis
}

\author{
Yue-Nan $\mathrm{Ni}^{1 \dagger}$, Jian Luo ${ }^{1 \dagger}, \mathrm{He} \mathrm{Yu^{2 }}$, Dan Liư ${ }^{2}$ Bin-Miao Liang ${ }^{1}$, Rong Yao ${ }^{3 *}$ and Zong-An Liang ${ }^{1 *}$
}

\begin{abstract}
Background: The effects of high flow nasal cannula (HFNC) on adult patients after extubation remain controversial. We aimed to further determine the effectiveness of HFNC in comparison to noninvasive positive pressure ventilation (NIPPV) and conventional oxygen therapy (COT).

Methods: The Pubmed, Embase, Medline, Cochrane Central Register of Controlled Trails (CENTRAL) as well as the Information Sciences Institute (ISI) Web of Science were searched for all the controlled study comparing HFNC with NIPPV and COT in adult patients after extubation. The primary outcome was rate of reintubation and the secondary outcomes were intensive care unit (ICU) mortality and length of ICU stay (ICU LOS).

Results: Eight trials with a total of 2936 patients were pooled in our final studies. No significant heterogeneity was found in outcome measures. Compared with COT, HFNC was associated with lower rate of reintubation $(Z=2.97, P=0.003)$, and the same result was found in the comparison between HFNC and NIPPV $(Z=0.87, P=0.38)$. As for the ICU mortality and ICU LOS, we did not find any advantage of HFNC over COT or NIPPV.

Conclusions: In patients after extubation, HFNC is a reliable alternative of NIPPV to reduce rate of reintubation compared with COT.
\end{abstract}

Keywords: High flow nasal cannula, Adult, Post-extubation, Meta-analysis, Mortality, Prognosis

\section{Background}

Mechanical ventilation is a life-saving method [1], which has been proved to improve gas exchange as well as decrease work of breathing due to fully or partially spontaneous breathing replacement. Unfortunately, invasive mechanical ventilation has been increasingly recognized to be associated with various adverse events, such as ventilator-associated pneumonia and barotrauma. Moreover, the hospital mortality of patients admitted into intensive care unit(ICU) remains as high as $30.7 \%[2,3]$. Timely extubation is one way of minimizing the morbidity [4]. However, it is estimated that 12 to $14 \%$ of patients who undergo planned extubation will require

\footnotetext{
* Correspondence: 1037070596@qq.com; liangzatg@126.com

${ }^{\dagger}$ Equal contributors

${ }^{3}$ Department of Emergency, Sichuan University, No. 37 Guoxue Alley,

Chengdu 610041, China

${ }^{1}$ Department of Respiratory and Critical Care, Sichuan University, No.37

Guoxue Alley, Chengdu 610041, China

Full list of author information is available at the end of the article
}

reintubation within 48 to $72 \mathrm{~h}$, most within the first $24 \mathrm{~h}[2,5-7]$.

NIPPV may prevent post-extubation respiratory failure and avoid reintubation if it is applied soon after extubation [8-12]. In addition, according to the most recent guidelines, preventive NIPPV was recommend in patients with high risk of reintubation [13]. However, numerous potential hazards, such as skin damage, eye irritation, interface intolerance, diet and expectoration interruption, might block the usage of NIPPV in clinical practice [14]. Thus, potential substitutions of NIPPV without the adverse events mentioned above are imperatively needed.

High-flow nasal cannula (HFNC) is a new technique of oxygen delivering, which delivers heated and humidified oxygen via special devices at a rate of up to $60 \mathrm{~L} / \mathrm{min}$. Because of the widely proved clinical efficacy together with easy application and good patient tolerance in critically ill infants and children, physicians began to focus on the potential roles of HFNC in improving clinical outcomes in 
adult patients [15]. However, contradictory conclusions were drawn in spite of large number of clinical trials. Fernandez and colleagues conducted a multicenter randomized controlled trial (RCT) in 155 high-risk non-hypercapnic patients and they found that HFNC could not decrease rate of reintubation compared with conventional oxygen therapy (COT) $(11 \%$ vs. $16 \%, P=0.5)$ [16]. On the contrary, a recent randomized trial by Hernández demonstrated that, compared with COT, HFNC could reduce the reintubation rate among extubated patients at low-risk (4.9\% vs. $12.2 \%, P$ $=0.004)$ [17].

Therefore, based on the disputed findings of HFNC in adult patients after extubation, we assumed that in terms of rate of reintubation, HFNC might be more effective than COT and might be a replacement of NIPPV. We conducted a meta-analysis of all published trials containing superiority test with COT or non-inferiority test with NIPPV, and aimed for identifying the impact of HFNC in improving the outcomes of patients after extubation.

\section{Methods}

\section{Search strategies}

From 1946 to July 2017, a comprehensive computer search was conducted in Pubmed, Embase, Medline, Cochrane Central Register of Controlled Trails (CENTRAL) and Information Sciences Institute (ISI) Web of Science using the keywords of "HFNC" or "high-flow nasal cannula" or "high-flow oxygen therapy" or "nasal high-flow oxygen therapy" and "NIPPV" or "non-invasive positive pressure ventilation" or "noninvasive positive pressure ventilation" or "non-invasive ventilation" or "noninvasive ventilation" or "oxygen therapy" or "COT" or "venturi mask" and "extubation" or "postextubation" without limitation in the publication type or language. We also reviewed the references listed in each identified article and manually searched the related articles to identify all eligible studies and minimize the potential publication bias.

\section{Inclusion and exclusion criteria}

Eligible clinical trials were identified based on the following criteria: 1) the subjects enrolled in each study included patients after extubation; 2) patients were divided into experimental group, in which HFNC oxygen therapy was applied, and control group, in which patients assigned to receive NIPPV or COT; 3 ) outcomes contained but not limited to mortality, rate of reintubation, length of stay (LOS) in ICU. We excluded studies if they were performed in animals or in patients less than 18 years old, or published as reviews or case reports.

\section{Study selection}

Two independent investigators ( $\mathrm{He} \mathrm{Yu}$ and $\mathrm{DL}$ ) performed the study selection in two phases. Firstly, they discarded duplicated and non-controlled studies by screening titles and abstracts. Secondly, eligible studies were extracted by reviewing full texts in accordance with the previously designed study inclusion criteria. Any disagreement was solved by mutual consensus in the presence of a third investigator(YN-Ni).

\section{Data extraction}

Independently, two data collectors extracted and recorded desirable information of each enrolled study in a standard form recommended by Cochrane, [18] which consisted of authors, publication year, study design, country, NCT No., population, demographic characteristics (age, gender, etc.), disease conditions (The Acute Physiologic and Chronic Health Evaluation II (APACHE II) and Simplified Acute Physiologic Score II (SAPS II)), outcome measures, and study results. For any missing data information, corresponding authors were contacted by email to request the full original data. Different opinions between the two collectors were determined by reaching a consensus or consulting a third investigator.

\section{Quality assessment}

For the assessment of risk of bias in estimating the study outcomes, we used the Cochrane risk of bias tool [18]. Each study was assessed for: 1) random sequence generation (selection bias); 2) allocation concealment(selection bias); 3) blinding of participants and personnel (performance bias); 4) blinding of related outcomes assessment (detection bias); 5) incomplete outcome data (attrition bias); 6) selective reporting (reporting bias); and 7) other biases. Two investigators conducted the quality assessment for the study methodology, independently and separately. Any divergence was resolved by mutual consensus in the presence of a third investigator.

\section{Statistical analysis}

Statistical analysis of our study was accomplished by an independent statistician using Cochrane systematic review software Review Manager (RevMan; Version 5.3.5; The Nordic Cochrane Centre, The Cochrane Collaboration, Copenhagen, 2014). We used Mann-Whitney U-test to verify hypothesis and rendered statistical significance as a $\mathrm{Z}$-value and $P$-value $<0.05$, and the results were displayed in Forest plots. Continuous variables were reported as mean and standard derivation (SD), while dichotomous variables were shown as frequency and proportion. An initial test for clinical, methodological and statistical heterogeneities was conducted, and we used the $X^{2}$ test with $P<0.1$ and $\mathrm{I}^{2}>50 \%$ to indicate significance. We also performed the sensitivity analysis to substitute alternative decisions or ranges of values for decisions that were arbitrary or unclear. Random-effects model was applied in the presence of statistical heterogeneity; otherwise, fixed 
effects model was used; for continuous data we calculated mean difference (MD) and 95\% confidence interval (CI), while for dichotomous data we calculated odds ratio (OR) and $95 \% \mathrm{CI}$.

\section{Results}

Initially 845 records were identified, of which 836 were extracted from electronic databases and 9 were extracted from reference lists review (Fig. 1). By screening the titles and abstracts, 806 studies were discarded for duplication $(n=208)$, animal experiments $(n=169)$, non-adult patients $(n=373)$, and non-controlled studies $(n=56)$. We searched the full-text articles for the remaining 39 studies, and eventually 8 trials [16,17, 19-24] were enrolled in our final analysis due to 11 studies were not reporting related outcomes, and 20 were not designed as expected.

\section{Study description}

All 8 studies compared the outcomes of HFNC alone with those of NIPPV or COT as a first-line therapy. Mortality was reported in 7 studies [16, 18-21], rate of reintubation was recorded in 8 studies [16, 17, 20-24], and ICU LOS was presented in 7 studies [16, 17, 20-24]. All the studies were RCTs $[15,16,18-21]$ Three studies enrolled the patients after cardiac surgery [19, 23, 24], 1 studies enrolled the patients after abdominal surgey [20], 2 studies enrolled the medical patients [20, 22] and 2 studies enrolled both medical and surgical patients [17, 21]. Details of each study were summarized in Table 1.

A total of 2936 patients were pooled from all the included trials in our final and meta-analysis, among which 1457 patients were treated with HFNC, 730 patients received NIPPV, and 749 patients used COT. The mean age ranged from 51 to 69 years old. Details of baseline characteristics of patients in each enrolled study were shown in Table 2.

\section{Quality assessment}

Quality assessment of the 6 enrolled studies showed that there was no bias in attribution, detection or reporting in 6 studies, but high bias existed in performance because blinding of patients and personnel seemed to be impossible in any study due to virtual practice issues. (Figs. 2 and 3) No studies were excluded for low quality or dubious decisions in the sensitivity analysis. The publication bias was not found (Fig.4).

\section{Heterogeneity}

Except for the rate of reintubation between HFNC and COT group $\left(\mathrm{I}^{2}=52 \%, \mathrm{X}^{2}=10.51, P=0.06\right)$, no statistical heterogeneity was found between HFNC and NIPPV group $\left(\mathrm{I}^{2}=0 \%, X^{2}=0.47, P=0.49\right)$, in the ICU mortality between HFNC and COT $\left(\mathrm{I}^{2}=0 \%, \chi^{2}=0.31, P=0.96\right)$, or between HFNC and NIPPV $\left(I^{2}=0 \%, X^{2}=0.03, P=0.87\right)$,

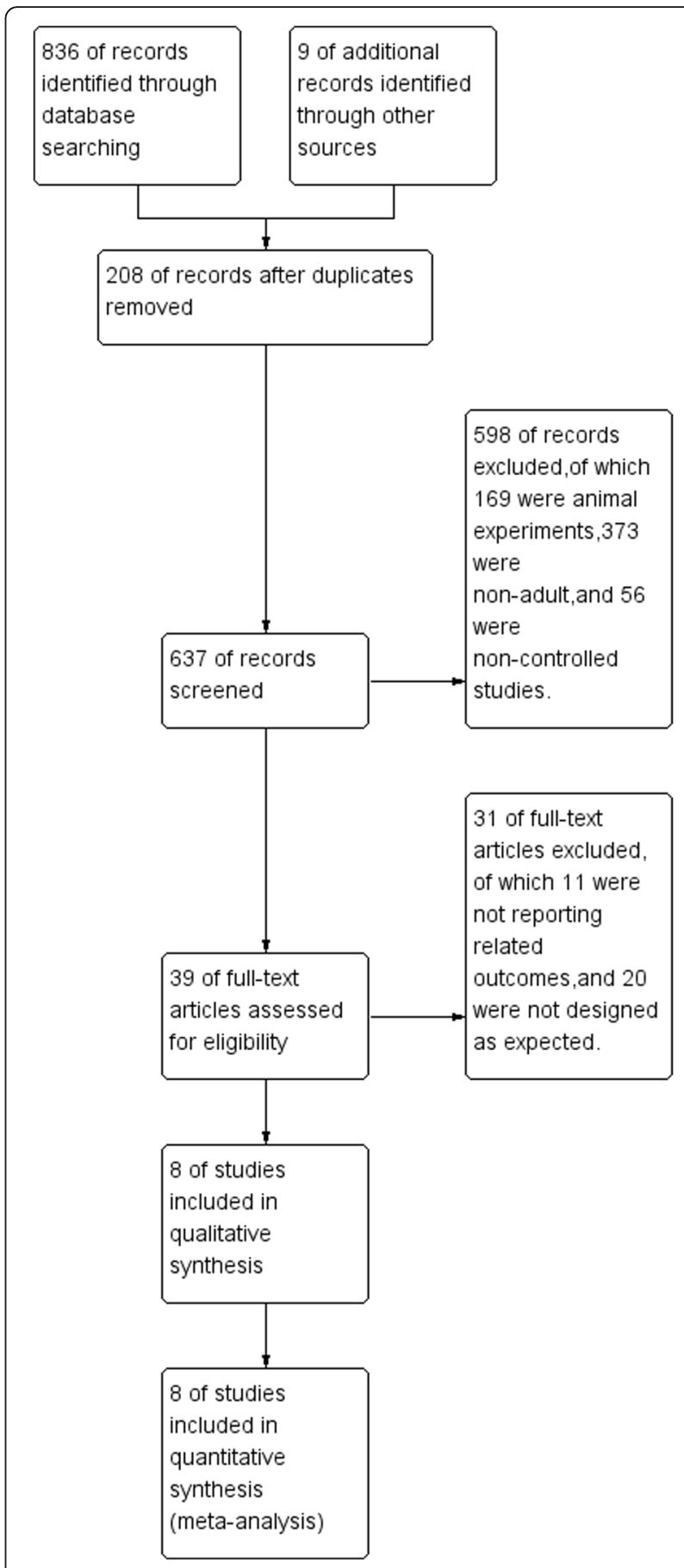

Fig. 1 Study flow diagram

and in the ICU LOS between HFNC and COT or NIPPV (HFNC vs. COT: $\mathrm{I}^{2}=23 \%, \chi^{2}=5.21, P=0.27$; HFNC vs. NIPPV: $\left.\mathrm{I}^{2}=0 \%, \mathrm{X}^{2}=0.11, P=0.75\right)$.

\section{Rate of reintubation}

Significant difference in the endotracheal intubation was found in HFNC treatment compared with COT (OR 0.52, 95\% CI 0.34 0.80, $\mathrm{Z}=2.97, P=0.003)$, but not in 
Table 1 Details of the eight enrolled studies

\begin{tabular}{|c|c|c|c|c|c|c|c|}
\hline Author(Year) & Study design & NCT No. & Country & Control & Population & Underlying disease & Outcome $^{a}$ \\
\hline Corley 2015 & $\begin{array}{l}\text { Randomised controlled } \\
\text { trial }\end{array}$ & ACTRN12610000942055 & Australia & $\begin{array}{l}\text { Standard } \\
\text { oxygen } \\
\text { therapy }\end{array}$ & 155 & Cardiac surgery & (2)(3) \\
\hline Fernández 2017 & $\begin{array}{l}\text { Randomised controlled } \\
\text { trial }\end{array}$ & NCT01820507 & Spain & COT & 155 & $\begin{array}{l}\text { Chronic obstructive } \\
\text { pulmonary disease, } \\
\text { heart failure }\end{array}$ & (1)(2)(3) \\
\hline Futier 2016 & $\begin{array}{l}\text { Multicenter randomized } \\
\text { trial }\end{array}$ & NCT01887015 & France & $\begin{array}{l}\text { Standard } \\
\text { oxygen } \\
\text { therapy }\end{array}$ & 220 & $\begin{array}{l}\text { Major abdominal } \\
\text { surgery }\end{array}$ & (1)(2)(3)(4) \\
\hline Hernández 2016 & Multicenter randomized trial & NCT01191489 & Spain & COT & 527 & $\begin{array}{l}\text { Medical,trauma, } \\
\text { surgical }\end{array}$ & (1)(2)(3)(4)(5) \\
\hline Hernández 2016 (2) & Multicenter randomized trial & NCT01191489 & Spain & NIPPV & 604 & $\begin{array}{l}\text { Medical,trauma, } \\
\text { surgical }\end{array}$ & (1)(2)(3)(4)(5) \\
\hline Maggiore 2014 & $\begin{array}{l}\text { Randomized controlled } \\
\text { open-label trial }\end{array}$ & NCT01575353 & Italian & $\begin{array}{l}\text { Venturi } \\
\text { mask }\end{array}$ & 105 & $\begin{array}{l}\text { Pneumonia, multiple } \\
\text { trauma, atelectasis, } \\
\text { shock, cardiogenic } \\
\text { pulmonary edema, } \\
\text { cardiac arrest, other }\end{array}$ & (1)(2)(3)(5) \\
\hline Parke 2013 & $\begin{array}{l}\text { Pragmatic randomized } \\
\text { controlled trial }\end{array}$ & ACTRN12610000973011 & $\begin{array}{l}\text { New } \\
\text { Zealand }\end{array}$ & $\begin{array}{l}\text { Simple } \\
\text { facemask } \\
\text { or nasal } \\
\text { prongs }\end{array}$ & 340 & Cardiac surgery & (2)(3)(6) \\
\hline Stéphan 2016 & $\begin{array}{l}\text { Multicente, r randomised, } \\
\text { noinferiorty trail }\end{array}$ & NCT01458444 & France & NIPPV & 830 & $\begin{array}{l}\text { Cardiothoracic } \\
\text { surgery }\end{array}$ & (1)(2)(3)(4)(5)(7) \\
\hline
\end{tabular}

\footnotetext{
a Outcome measures include:(1)mortality;(2rate of endotracheal intubation; (3length of ICU stay;(4adverse events;(5respiratory variables;(@patient comfort; (])dyspnea scale

$A E C O P D$ acute exacerbation of chronic obstructive pulmonary disease; $A R D S$ acute respiratory distress syndrom; $A R F$ acute respiratory failure; $C O P D$ chronic obstructive pulmonary disease;COT conventional oxygen therapy; HFNC high flow nasal cannula; NIPPV noninvasive positive pressure ventilation; NR not report; SIRS systemic inflammatory response syndrome
}

the comparison with NIPPV (OR 1.13, 95\% CI $0.86 \sim 1.49, \mathrm{Z}=0.87, P=0.38$ ) as well as in overall effects (OR 0.89, 95\% CI 0.71 1.13, $\mathrm{Z}=0.94, P=0.35$ ) (Fig.5).

\section{ICU mortality}

We did not find significant difference in ICU mortality between treatment with HFNC and COT (OR 0.93, 95\% CI $0.47 \sim 1.86, Z=0.19, P=0.85$ ) or NIPPV (OR 1.20, 95\% CI $0.78 \sim 1.85, Z=0.83, P=0.40$ ), nor in overall effects (OR 1.12, 95\%CI 0.78 1.61, $\mathrm{Z}=0.60, P=0.55$ ) (Fig.6).

\section{ICU los}

Figure 7 showed that differences of ICU LOS were not significant between HFNC and COT (OR 0.71, 95\% CI -0.60 2.02, $Z=1.06, P=0.29$ ) or NIPPV (OR -0.49, 95\%CI $-3.51 \sim 2.53, Z=0.32, P=0.75)$, nor in overall effects (OR 0.52, 95\%CI $-0.69 \sim 1.72, \mathrm{Z}=0.84, \mathrm{P}=0.4$ ).

\section{Discussion}

We conducted the meta-analysis to compare the impact of HFNC, COT and NIPPV on rate of reintubation, ICU

Table 2 Baseline characteristics of patients

\begin{tabular}{|c|c|c|c|c|c|c|c|c|}
\hline & HFNC & & & & Control & & & \\
\hline Author (Year) & $\begin{array}{l}\text { Age,Years } \\
\text { Mean (SD) }\end{array}$ & Man n,(\%) & $\begin{array}{l}\text { SAPS \| } \\
\text { Mean(SD) }\end{array}$ & $\begin{array}{l}\text { APACHE II } \\
\text { Mean(SD) }\end{array}$ & $\begin{array}{l}\text { Age,Years } \\
\text { Mean(SD) }\end{array}$ & Man, n,(\%) & $\begin{array}{l}\text { SAPS II, } \\
\text { Mean(SD) }\end{array}$ & $\begin{array}{l}\text { APACHE II, } \\
\text { Mean(SD) }\end{array}$ \\
\hline Corley 2015 & $63(11.4)$ & $58(72.0 \%)$ & NR & 15(3.6) & $65(11.1)$ & $56(76.0 \%)$ & $N R$ & $15.0(3.9)$ \\
\hline Fernandez 2017 & $67.3(12.1)$ & $46(59.0 \%)$ & NR & $11(5.5)$ & $69.7(13.0)$ & $55(71.0 \%)$ & $N R$ & $10.0(6.7)$ \\
\hline Futier 2016 & $62(12.0)$ & $61(56.0 \%)$ & NR & $N R$ & $61.0(13.0)$ & $64(57.0 \%)$ & $N R$ & NR \\
\hline Hernández 2016 & $51(13.1)$ & 164(62.1\%) & NR & 7 & $51.8(12.2)$ & $153(58.2 \%)$ & $N R$ & 7 \\
\hline Hernández 2016(2) & $64.6(15.4)$ & $186(64.1)$ & NR & 11 & $64.4(15.8)$ & $202(64.3)$ & NR & 10 \\
\hline Maggiore 2014 & $64(17.0)$ & $33(62.3 \%)$ & $44(16)$ & $N R$ & $65.0(18.0)$ & $35(67.3 \%)$ & $43.0(14.0)$ & NR \\
\hline Parke 2013 & 65 & $129(76.3 \%)$ & NR & $N R$ & 66.0 & $129(75.4 \%)$ & $N R$ & NR \\
\hline Stéphan 2016 & 63.8 & 273(65.9\%) & 29 & $N R$ & 63.9 & 278(66.8\%) & 28.8 & NR \\
\hline
\end{tabular}

APACHE The Acute Physiologic and Chronic Health Evaluation; COT conventional oxygen therapy; HFNC high flow nasal cannula; NIPPV noninvasive positive pressure ventilation; NR not report; SAPS Simplified Acute Physiologic Score; SD standard derivation; SIRS systemic inflammatory response syndrome 


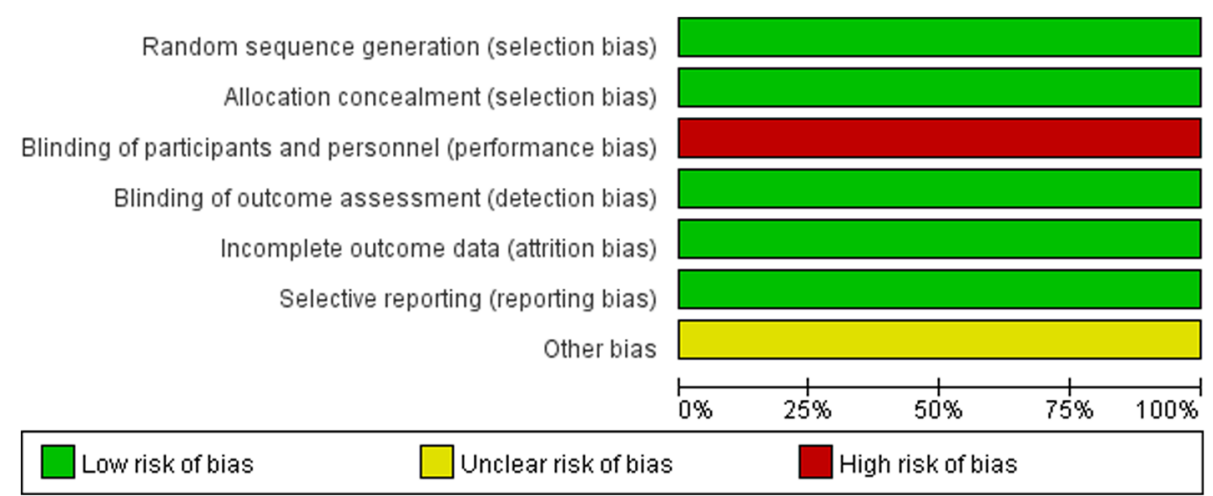

Fig. 2 Risk of bias graph

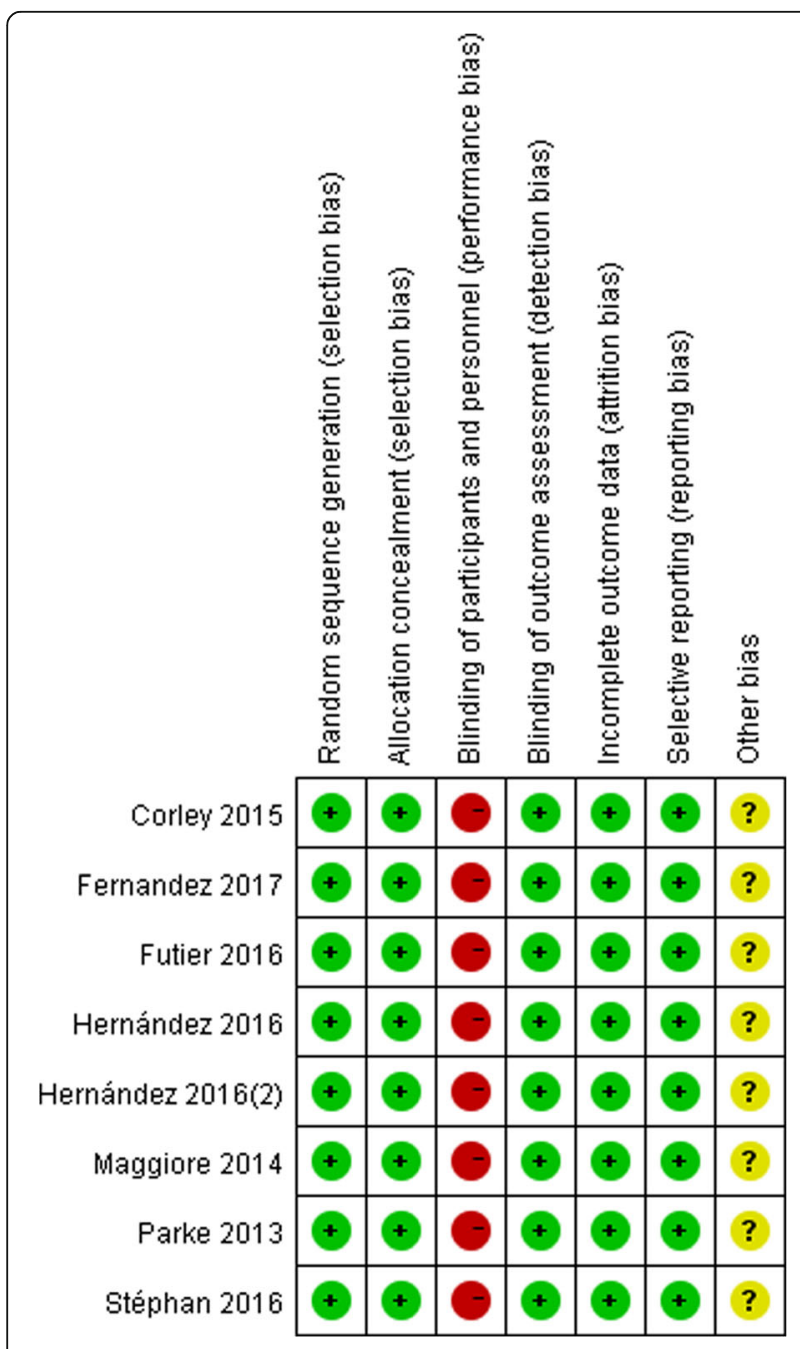

Fig. 3 Risk of bias summary mortality and ICU LOS. The results showed that HFNC could decrease the rate of reintubation in adult patients after extubation compared with $\mathrm{COT}$, which was equivalent to NIPPV. However, it could not decrease the ICU mortality or the ICU LOS .

HFNC is an excellent oxygen therapy due to its appealing capacity in easy usage, good tolerance and oxygenation improvement $[15,17]$. However, no definite conclusions could be drawn because of the inconsistent findings in different studies, which results in our pooled analysis to determine roles of HFNC in improving the outcomes of patients after extubation. In our study, compared with those who used COT, a significant lower need of reintubation in patients after extubation receiving HFNC was presented. The mechanisms of the lower rate of reintubation can be explained as the followings. First of all, as mechanical ventilation will leads to atelectasis even after extubation $[25,26]$, a positive and expiratory pressure(PEEP) $\left(2-5 \mathrm{cmH}_{2} \mathrm{O}\right)$ generated by high flow can lead to continuous alveolar recruitment, reduction of airway collapse and improvement of the ventilation-perfusion mismatch [27-30]. Hence larger end expiratory lung volume was observed in patients with HFNC than COT [31]. In addition, the heated humidification closely to physiological conditions preserves the mucosal function and facilitates secretion clearance, thereby further decreasing the risk of atelectasis and improving the oxygenation [32]. Second, adequate minute ventilation and sufficient oxygenation guaranteed by HFNC via delivering a continuous high flow of oxygen accompanied with a higher tidal volume and improved inspiratory flow dynamics [33-35]. Thereby HFNC can decrease respiratory rate and work of breathing [36]. Third, potential pharyngeal dead space washout effect results in a faster decrease of the carbon dioxide and thus a greater fraction of minute ventilation participates in gas exchange [37, 38]. Last, contrary to the unstability $\mathrm{FiO}_{2}$ delivered by COT because the entertainment of room air and dilution of the inspired oxygen, constant concentration of oxygen can be delivered to patients due to the high flow 


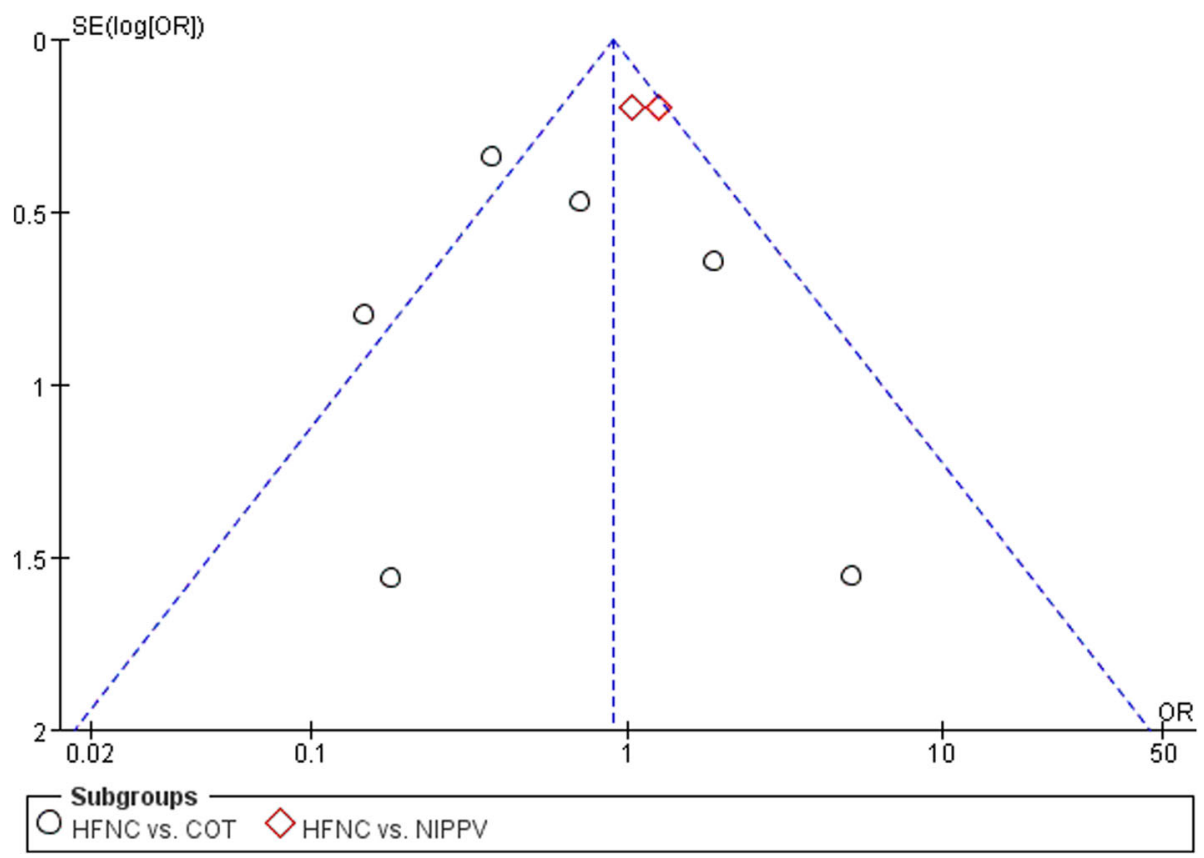

Fig. 4 Fig. 4 Funnel plot for publicationbias

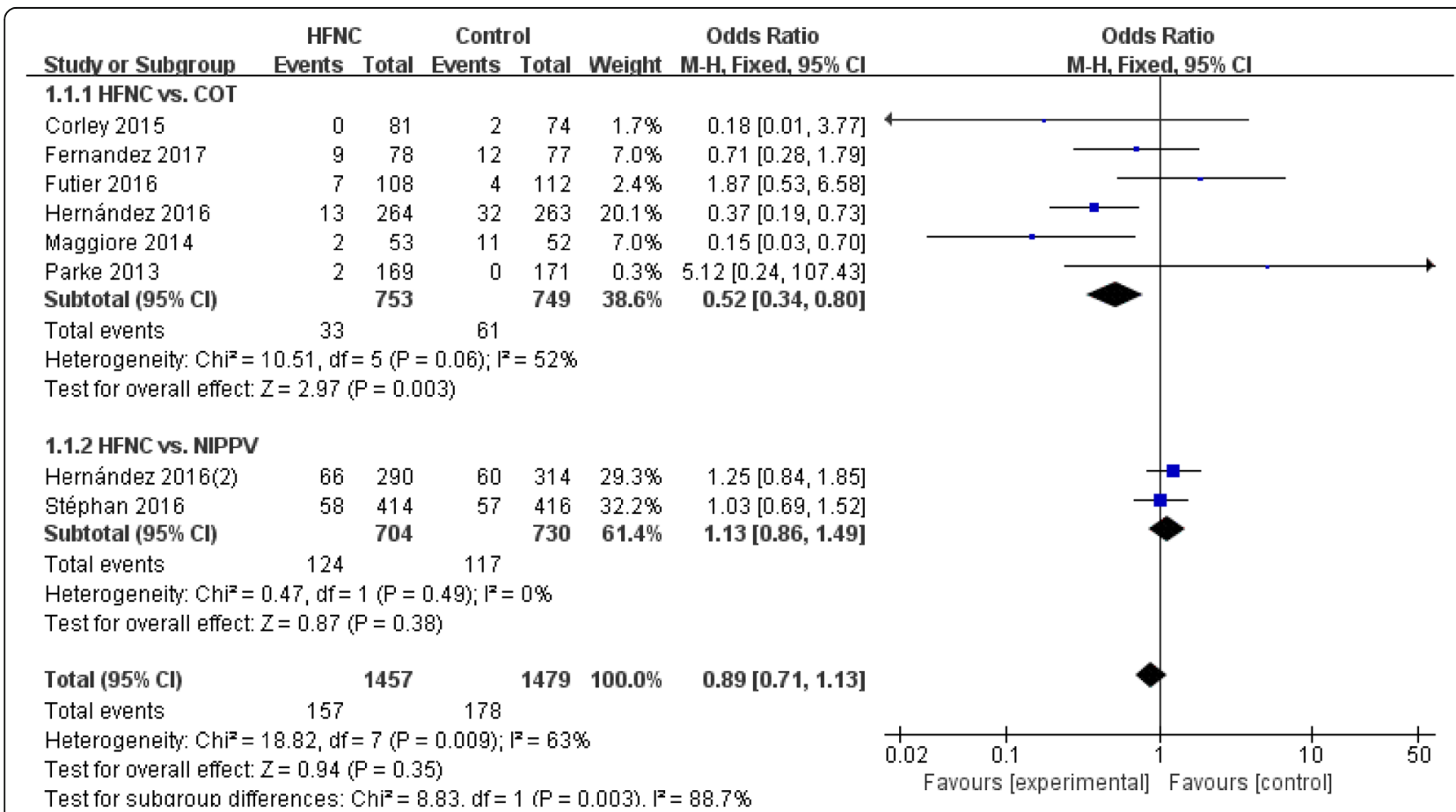

Fig. 5 Rate of reintubation. COT, conventional oxygen therapy; Cl, confidence interval; HFNC, high-flow nasal cannula; ICU, intensive care unit; NIPPV, noninvasive positive pressure ventilation; SD, standard derivation 


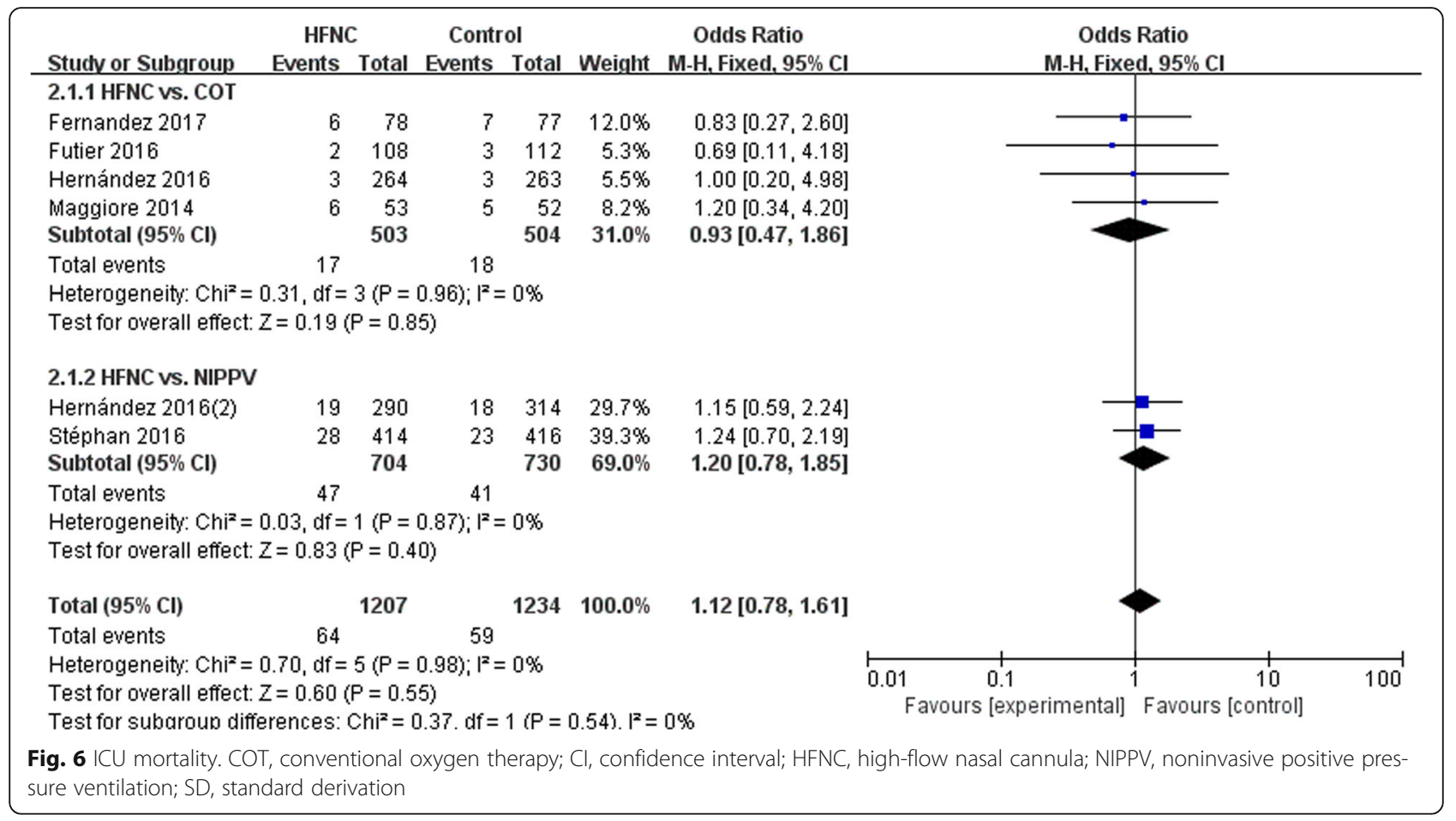

and oxygen reservoir within the upper airway [39]. Thus, the risk of insufficient oxygen flow supply for patients, which is common in COT, could be reduced in HFNC [40, 41].

The results of our study were totally different from the previous analyses [42-44], which found no different between HFNC and COT. First of all, we included most recent studies. Second, we only focus on the patients after extubation and surgery, while the other two analyses also included the patients before MV [42, 44]. The respiratory failure often resulted from the initial disease which often had been solved in the patients after extubation. On the contrary, patients after surgery or extubation need respiratory support mainly because of low cough strength and level of consciousness $[5,45]$. Third, we only included RCTs, and in the previous studies, non-RCTs were also included.

However, our meta-analysis also indicated that HFNC could not further decrease ICU mortality or ICU LOS compared with COT. As we know, except for respiratory

\begin{tabular}{|c|c|c|c|c|c|c|c|c|c|}
\hline \multirow[b]{2}{*}{ Stucty or Subgroup } & \multicolumn{3}{|c|}{ Experimental } & \multicolumn{2}{|c|}{ Control } & \multirow[b]{2}{*}{ Total } & \multirow[b]{2}{*}{ Weight } & \multirow{2}{*}{$\begin{array}{c}\text { Mean Difference } \\
\text { IV, Fixed, 95\% Cl }\end{array}$} & \multirow{2}{*}{$\begin{array}{l}\text { Mean Difference } \\
\text { V. Fixed, } 95 \% \mathrm{Cl}\end{array}$} \\
\hline & Mean & SD & Total & Mean & SD & & & & \\
\hline \multicolumn{10}{|l|}{ 3.1.1 HFNC vs. COT } \\
\hline Fernandez 2017 & 12 & 13.33 & 78 & 14 & 5.93 & 77 & $13.8 \%$ & $-2.00[-5.24,1.24]$ & \\
\hline Futier 2016 & 6 & 5.93 & 108 & 5 & 7.41 & 112 & $46.3 \%$ & $1.00[-0.77,2.77]$ & \\
\hline Hernández 2016 & 6 & 24.87 & 264 & 6 & 28.96 & 263 & $6.8 \%$ & $0.00[-4.61,4.61]$ & \\
\hline Maggiore 2014 & 11.7 & 10.2 & 53 & 10.4 & 8.5 & 52 & $11.3 \%$ & $1.30[-2.29,4.89]$ & \\
\hline Parke 2013 & 33.4 & 22.8 & 169 & 28.9 & 24 & 171 & $5.9 \%$ & $4.50[-0.48,9.48]$ & 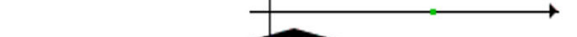 \\
\hline Subtotal $(95 \% \mathrm{Cl})$ & & & 672 & & & 675 & $84.1 \%$ & $0.71[-0.60,2.02]$ & \\
\hline \multicolumn{10}{|c|}{$\begin{array}{l}\text { Heterogeneity: } \text { Chi }^{2}=5.21, \mathrm{df}=4(\mathrm{P}=0.27) ; \mathrm{I}^{2}=23 \% \\
\text { Test for overall effect: } Z=1.06(P=0.29)\end{array}$} \\
\hline \multicolumn{10}{|l|}{ 3.1.2 HFNC vs. NIPPV } \\
\hline Hernández 2016(2) & 3 & 21.72 & 290 & 4 & 31.64 & 314 & $7.8 \%$ & $-1.00[-5.30,3.30]$ & \\
\hline Stéphan 2016 & 6 & 31.22 & 416 & 6 & 31.14 & 414 & $8.1 \%$ & $0.00[-4.24,4.24]$ & \\
\hline Subtotal $(95 \% \mathrm{Cl})$ & & & 706 & & & 728 & $15.9 \%$ & $-0.49[-3.51,2.53]$ & \\
\hline \multicolumn{10}{|c|}{$\begin{array}{l}\text { Heterogeneity: } \mathrm{Chi}^{2}=0.11, \mathrm{df}=1(\mathrm{P}=0.75) ; \mathrm{I}^{2}=0 \% \\
\text { Test for overall effect: } Z=0.32(\mathrm{P}=0.75)\end{array}$} \\
\hline Total $(95 \% \mathrm{Cl})$ & & & 1378 & & & 1403 & $100.0 \%$ & $0.52[-0.69,1.72]$ & \\
\hline \multicolumn{9}{|c|}{$\begin{array}{l}\text { Heterogeneity: } C h i^{2}=5.83, d f=6(P=0.44) ; I^{2}=0 \% \\
\text { Test for overall effect: } Z=0.84(P=0.40) \\
\text { Test for subaroun differences: } \mathrm{Chi}^{2}=0.51 . \mathrm{df}=1(\mathrm{P}=0.47) . \mathrm{I}^{2}=0 \%\end{array}$} & $\begin{array}{ccccc}-4 & 1 & 1 & 1 & 1 \\
\text { Favours [experimental] } & \text { Favours [control] }\end{array}$ \\
\hline \multicolumn{10}{|c|}{$\begin{array}{l}\text { Fig. } 7 \text { ICU LOS. COT, conventional oxygen therapy; CI, confidence interval; HFNC, high-flow nasal cannula; ICU, intensive care unit; LOS, length of } \\
\text { stay; NIPPV, noninvasive positive pressure ventilation; SD, standard derivation }\end{array}$} \\
\hline
\end{tabular}


status, numerous factors, especially the concomitant complications such as the acute liver injury and cardiac impairment, may contribute to mortality and ICU LOS $[46,47]$. Moreover, it is undeniable that medical resources as well as expenditures are tightly related to the disease outcomes, such as bed availability in general wards and insurance status, which in some extent may offset the positive effects of HFNC.

It has been reported that NIPPV could improve oxygenation and ventilation as well as reduce the risk of respiratory failure in patients after extubation [8-13]. It is believed that NIPPV possessed potential benefits to provide a relatively consistent and wider range of $\mathrm{FiO}_{2}$ compared with COT [48]. Moreover, NIPPV could also create an extrinsic PEEP to recruit the collapsed alveoli [49-51]. However, as mentioned above, the limitations of NIPPV due to the adverse events continuously urge physicians and researchers to explore and refine a new oxygen delivery system to prevent potential compromises induced by NIPPV but preserve similar efficiency.

Based on precedent evidence that NIPPV could reduce the rate of intubation in patients after extubation compared with COT $[8,52]$ as well as similar findings in HFNC in our study, we performed a non-inferiority test between HFNC and NIPPV to further elucidate the potential clinical implications of HFNC. In our metaanalysis, compared with NIPPV, HFNC did not increase the rate of reintubation, which we considered to be attributed to similar effects on respiratory mechanics and gas exchange like providing accuracy $\mathrm{FiO}_{2}$, extrinsic PEEP and guaranteeing sufficient minute ventilation [28-30, 32, 40, 49-51]. Moreover, a lot of studies also reported some advantages of HFNC compared with NIPPV. For example, HFNC can be better tolerated than NIPPV because of more comfortable resulted from a stable flow with warm and humidified gas to reduce the sense of dryness and facilitate secretion clearance [53, 54]. At the same time, the patient-ventilator interaction interface of HFNC was more friendly and would not disturb speaking or eating [55]. Therefore, we might conclude that HFNC is a good replacement of NIPPV in patients after extubation.

However, some clinical heterogeneity existed in our analysis: 1) different end point. Both of the following up time and the primary endpoint were varied among the studies. All of these differences caused the heterogeneity; 2) Heterogeneous treatment strategies. The flow of HFNC and the length of the usage were not unified among studies; 3 ) Mixed patients. The reasons of MV before extubation were different in enrolled studies including the medical problems and surgery. Moreover, the risks of reintubation were varied in different studies.

Our study has some limitations. Firstly, bias cannot be completely ruled out because blinding was not feasible. Second, the flow of HFNC, the length of HFNC using time after extubation, oxygen therapy interface, end point and following up time were different in our enrolled studies, which may further impede the clinical practice. Third, the underlying diseases of patients in our study were mixed including the ones after surgery and extubation, and even the risk of reintubation was varied. Thus, the second and third limitations contribute to the statistic and clinical heterogeneity of our analysis, which would influence the application of our study. Therefore, future studies are still necessary to further establish standardized application protocols.

\section{Conclusions}

Compared with COT, HFNC could reduce rate of reintubation in patients after extubation, in spite of no benefit in ICU mortality or ICU LOS. It can be considered as a reliable substitute of NIPPV due to similar respiratory mechanics and equivalent clinical outcomes but better compliance and fewer complications.

\section{Abbreviations \\ APACHE: The Acute Physiologic and Chronic Health Evaluation; ARDS: Acute respiratory distress syndrome; ARF: Acute respiratory failure; CENTRAL: Cochrane Central Register of Controlled Trails; Cl: Confidence interval; $\mathrm{COT}$ : Conventional oxygen therapy; $\mathrm{FiO}_{2}$ : Fraction of inspired oxygen; HFNC: High flow nasal cannula; ICU: Intensive care unit; ISI: Information Sciences Institute; LOS: Length of stay; MD: Mean difference; NIPPV: Noninvasive positive pressure ventilation; Ol: Oxygen index; OR: Odds ratio; $\mathrm{PaO}_{2}$ : Partial pressure of arterial oxygen; PEEP: Positive end expiratory pressure; $\mathrm{RCT}$ : Randomized controlled trial; $\mathrm{SaO}_{2}$ : Arterial oxygen saturation; SAPS: Simplified Acute Physiologic Score; SD: Standard derivation}

\section{Acknowledgements}

We thank Professor Dongtao Lin (College of Foreign Languages, Sichuan University), who is specialized in biomedical writing and editing, for copyediting this manuscript.

\section{Funding}

Sichuan Science and Technology Agency Grant (2014SZ0010) provides finacial support during the literature seaiching and data collection, Ministry of Science and Technology of the People's Republic of China (2013BAl09B09 and 2015BAl12B10) provide financial suport during the language revising and publication.

\section{Availability of data and materials}

Data sharing is not applicable to this article as no datasets were generated or analysed during the current study.

\section{Authors' contributions \\ Y-NN and $J L$ designed the study and drafted the manuscript; $\mathrm{He} \mathrm{Yu,} \mathrm{DL}$ and B-ML conducted the literature searching, data analysis and revised it critically for important intellectual content; RY and Z-AL made the decision to submit the report for publication. All authors read, approved the final manuscript and agreed to be accountable for all aspects of the work in ensuring that questions related to the accuracy or integrity of any part of the work are appropriately investigated and resolved.}

Ethics approval and consent to participate

Each enrolled trial was approved by the corresponding institutional Ethical Committee, and all participants provided written informed consent.

Consent for publication

Not applicable. 


\section{Competing interests}

None of all authors have any financial or non-financial competing interests in this manuscript.

\section{Publisher's Note}

Springer Nature remains neutral with regard to jurisdictional claims in published maps and institutional affiliations.

\section{Author details}

${ }^{1}$ Department of Respiratory and Critical Care, Sichuan University, No.37 Guoxue Alley, Chengdu 610041, China. ${ }^{2}$ Department of Critical Care Medicine, Sichuan University, No. 37 Guoxue Alley, Chengdu 610041, China. ${ }^{3}$ Department of Emergency, Sichuan University, No. 37 Guoxue Alley, Chengdu 610041, China.

Received: 28 March 2017 Accepted: 10 November 2017

Published online: 17 November 2017

\section{References}

1. Schettino G, Altobelli N, Kacmarek RM. Noninvasive positive-pressure ventilation in acute respiratory failure outside clinical trials: experience at the Massachusetts General Hospital. Crit Care Med. 2008 Feb;36(2):441-7.

2. Esteban A, Anzueto A, Frutos F, et al. Characteristics and outcomes in adult patients receiving mechanical ventilation: a 28-day international study. JAMA. 2002;287(3):345-55.

3. Kollef $\mathrm{MH}$. What is ventilator-associated pneumonia and why is it important? Respir Care. 2005;50(6):714-21.

4. Pingleton SK. Complications of acute respiratory failure. Am Rev Respir Dis. 1988;137(6):1463-93.

5. Thille AW, Boissier F, Ben Ghezala H, et al. Risk factors for and prediction by caregivers of extubation failure in ICU patients: a prospective study. Crit Care Med. 2015;43(3):613-20.

6. Frutos-Vivar F, Ferguson ND, Esteban A, et al. Risk factors for extubation failure in patients following a successful spontaneous breathing trial. Chest. 2006;130(6):1664-71.

7. Thille AW, HaORois A, Schortgen F, et al. Outcomes of extubation failure in medical intensive care unit patients. Crit Care Med. 2011:39(12):2612-8.

8. Nava S, Gregoretti C, Fanfulla F, et al. Noninvasive ventilation to prevent respiratory failure after extubation in high-risk patients. Crit Care Med. 2005;33(11):2465-70

9. Ferrer M, Valencia M, Nicolas JM, et al. Early noninvasive ventilation averts extubation failure in patients at risk: a randomized trial. Am J Respir Crit Care Med. 2006;173(2):164-70. Epub 2005 Oct 13

10. Ferrer M, Sellarés J, Valencia M, et al. Non-invasive ventilation after extubation in hypercapnic patients with chronic respiratory disorders: randomised controlled trial. Lancet. 2009;374(9695):1082-8.

11. Burns KE, Meade MO, Premji A, et al. Noninvasive positive-pressure ventilation as a weaning strategy for intubated adults with respiratory failure. Cochrane Database Syst Rev. 2013;12:CD004127.

12. El-Solh AA, Aquilina $A$, Pineda $L$, et al. Noninvasive ventilation for prevention of post-extubation respiratory failure in obese patients. Eur Respir J. 2006;28(3):588-95.

13. Schmidt GA, Girard TD, Kress JP, et al. Liberation from mechanical ventilation in critically ill adults: executive summary of an official American College of Chest Physicians/American Thoracic Society clinical practice guideline. Chest. 2017;151(1):160-5

14. Hill NS. Complications of noninvasive ventilation. Respir Care. 2000; 45(5):480-1. Review

15. Lee $J H$, Rehder KJ, Williford $L$, et al. Use of high flow nasal cannula in critically ill infants, children, and adults: a critical review of the literature. Intensive Care Med. 2013:39(2):247-57.

16. Fernandez R, Subira C, Frutos-Vivar F, et al. High-flow nasal cannula to prevent postextubation respiratory failure in high-risk non-hypercapnic patients: a randomized multicenter trial. Ann Intensive Care. 2017;7(1):47.

17. Hernández G, Vaquero C, González P, et al. Effect of Postextubation highflow nasal Cannula vs conventional oxygen therapy on Reintubation in lowrisk patients: a randomized clinical trial. JAMA. 2016;315(13):1354-61.

18. Higgins JP, Green S. eds. Cochrane handbook for systematic reviews of interventions version 5.1.0. Oxford: the Cochrane collaboration; 2011 Updated March 2011. http://training.cochrane.org/handbooks. Accessed 20 Mar 2011
19. Corley A, Bull T, Spooner AJ, et al. Direct extubation onto high-flow nasal cannulae post-cardiac surgery versus standard treatment in patients with a BM 230: a randomised controlled trial. Intensive Care Med. 2015;41(5):887-94.

20. Futier E, Paugam-Burtz C, Godet T, et al. Effect of early postextubation highflow nasal cannula vs conventional oxygen therapy on hypoxaemia in patients after major abdominal surgery: a French multicentre randomised controlled trial (OPERA). Intensive Care Med. 2016;42(12):1888-98.

21. Hernández G, Vaquero C, Colinas L, et al. Effect of Postextubation High-Flow Nasal Cannula vs Noninvasive Ventilation on Reintubation and Postextubation Respiratory Failure in High-Risk Patients: A Randomized Clinical Trial. JAMA. 2016;316(15):1565-74.

22. Maggiore SM, Idone FA, Vaschetto $R$, et al. Nasal high-flow versus Venturi mask oxygen therapy after extubation. Effects on oxygenation, comfort, and clinical outcome. Am J Respir Crit Care Med. 2014;190(3):282-8.

23. Parke R, McGuinness S, Dixon R, et al. Open-label, phase II study of routine high-flow nasal oxygen therapy in cardiac surgical patients. Br J Anaesth. 2013;111(6):925-31.

24. Stéphan $F, B a O R u c a n d ~ B$, Petit $P$, et al. High-flow nasal oxygen vs noninvasive positive airway pressure in hypoxemic patients after cardiothoracic surgery: a randomized clinical trial. JAMA. 2015;313(23):2331-9.

25. Joyce $C J$, Williams $A B$. Kinetics of absorption atelectasis during anesthesia: a mathematical model. J Appl Physiol (1985). 1999;86(4):1116-25.

26. Edmark $L$, Auner $U$, Enlund $M$, et al. Oxygen concentration and characteristics of progressive atelectasis formation during anaesthesia. Acta Anaesthesiol Scand. 2011;55(1):75-81.

27. Corley A, Caruana LR, Barnett AG, et al. Oxygen delivery through high-flow nasal cannulae increase end-expiratory lung volume and reduce respiratory rate in post-cardiac surgical patients. Br J Anaesth. 2011;107(6):998-1004.

28. Parke RL, Eccleston ML, McGuinness SP. The effects of flow on airway pressure during nasal high-flow oxygen therapy. Respir Care. 2011;56(8):1151-5.

29. Parke R, McGuinness S, Eccleston M. Nasal high-flow therapy delivers low level positive airway pressure. Br J Anaesth. 2009;103(6):886-90.

30. Ritchie JE, Williams AB, Gerard C, et al. Evaluation of a humidified nasal high-flow oxygen system, using oxygraphy, capnography and measurement of upper airway pressures. Anaesth Intensive Care. 2011;39(6):1103-10.

31. Riera J, Pérez P, Cortés J, et al. Effect of high-flow nasal cannula and body position on end-expiratory lung volume: a cohort study using electrical impedance tomography. Respir Care. 2013;58(4):589-96.

32. Kernick J, Magarey J. What is the evidence for the use of high flow nasal cannula oxygen in adult patients admitted to critical care units? A systematic review. Aust Crit Care. 2010;23(2):53-70.

33. Lemiale $V$, Mokart $D$, Mayaux J, et al. The effects of a 2-h trial of high-flow oxygen by nasal cannula versus Venturi mask in immunocompromised patients with hypoxemic acute respiratory failure: a multicenter randomized trial. Crit Care. 2015;19:380

34. Mündel T, Feng S, Tatkov $S$, et al. Mechanisms of nasal high flow on ventilation during wakefulness and sleep. J Appl Physiol (1985). 2013;114(8):1058-65.

35. Frizzola M, Miller TL, Rodriguez ME, et al. High-flow nasal cannula: impact on oxygenation and ventilation in an acute lung injury model. Pediatr Pulmonol. 2011:46(1):67-74.

36. Itagaki T, Okuda N, Tsunano Y, et al. Effect of high-flow nasal cannula on thoraco-abdominal synchrony in adult critically ill patients. Respir Care. 2014;59(1):70-4.

37. Groves N, Tobin A. High flow nasal oxygen generates positive airway pressure in adult volunteers. Aust Crit Care. 2007;20(4):126-31.

38. Ward JJ. High-flow oxygen administration by nasal cannula for adult and perinatal patients. Respir Care. 2013;58(1):98-122.

39. Chanques G, Riboulet F, Molinari N, et al. Comparison of three high flow oxygen therapy delivery devices: a clinical physiological cross-over study. Minerva Anestesiol. 2013;79(12):1344-55. Epub 2013 Jul 15

40. O'Driscoll BR, Howard LS, Davison AG, et al. BTS quideline for emergency oxygen use in adult patients. Thorax. 2008;63(Suppl 6):vi1-68.

41. Jones HA, Turner SL, Hughes JM. Performance of the large-reservoir oxygen mask (Ventimask). Lancet. 1984;1(8392):1427-31.

42. Nedel WL, Deutschendorf C. Moraes Rodrigues Filho E. High-flow nasal Cannula in critically ill subjects with or at risk for respiratory failure: a systematic review and meta-analysis. Respir Care. 2017;62(1):123-32.

43. Corley A, Rickard CM, Aitken LM, et al. High-flow nasal cannulae for respiratory support in adult intensive care patients. Cochrane Database Syst Rev. 2017;5:CD010172. 
44. Maitra S, Som A, Bhattacharjee S, et al. Comparison of high-flow nasal oxygen therapy with conventional oxygen therapy and noninvasive ventilation in adult patients with acute hypoxemic respiratory failure: a meta-analysis and systematic review. J Crit Care. 2016;35:138-44.

45. Namen AM, Ely EW, Tatter SB, et al. Predictors of successful extubation in neurosurgical patients. Am J Respir Crit Care Med. 2001;163(3Pt 1):658-64.

46. Li G, Cook DJ, Thabane L, et al. Risk factors for mortality in patients admitted to intensive care units with pneumonia. Respir Res. 2016;17(1):80

47. Marshall JC, Cook DJ, Christou NV, et al. Multiple organ dysfunction score: a reliable descriptor of a complex clinical outcome. Crit Care Med. 1995;23(10):1638-52.

48. Papazian L, Corley A, Hess D, et al. Use of high-flow nasal cannula oxygenation in ICU adults: a naORative review. Intensive Care Med. 2016;42(9):1336-49.

49. Keenan SP, Sinuff T, Cook DJ, et al. Does noninvasive positive pressure ventilation improve outcome in acute hypoxemic respiratory failure? A systematic review. Crit Care Med. 2004;32(12):2516-23.

50. Luo J, Wang MY, Zhu H, et al. Can non-invasive positive pressure ventilation prevent endotracheal intubation in acute lung injury/acute respiratory distress syndrome? A meta-analysis Respirology. 2014;19(8):1149-57.

51. Xu X, Yuan B, Liang $Q$, et al. Noninvasive ventilation for acute lung injury a meta-analysis of randomized controlled trials. Heart Lung. 2016;45(3):249-57.

52. Jaber $S$, Lescot T, Futier $E$, et al. Effect of noninvasive ventilation on tracheal Reintubation among patients with hypoxemic respiratory failure following abdominal surgery: a randomized clinical trial. JAMA. 2016;315(13):1345-53.

53. Dysart K, Miller TL, Wolfson MR, et al. Research in high flow therapy: mechanisms of action. Respir Med. 2009;103(10):1400-5.

54. Gotera C, Díaz Lobato S, Pinto T, et al. Clinical evidence on high flow oxygen therapy and active humidification in adults. Rev Port Pneumol. 2013;19(5):217-27.

55. Wettstein RB, Shelledy DC, Peters II. Delivered oxygen concentrations using low-flow and high-flow nasal cannulas. Respir Care. 2005;50(5):604-9.

\section{Submit your next manuscript to BioMed Central and we will help you at every step:}

- We accept pre-submission inquiries

- Our selector tool helps you to find the most relevant journal

- We provide round the clock customer support

- Convenient online submission

- Thorough peer review

- Inclusion in PubMed and all major indexing services

- Maximum visibility for your research

Submit your manuscript at www.biomedcentral.com/submit 